\title{
Comprehensive geriatric assessment in the emergency department
}

This article was published in the following Dove Press journal:

Clinical Interventions in Aging

24 November 2014

Number of times this article has been viewed

\section{Graham Ellis' \\ Trudi Marshall ${ }^{2}$ \\ Claire Ritchie ${ }^{2}$}

'Medicine for the Elderly, Monklands Hospital, Airdrie, Scotland, UK; ${ }^{2}$ Kirklands Hospital, Bothwell, Scotland, UK
Correspondence: Graham Ellis Medicine for the Elderly, Monklands Hospital, Airdrie, Scotland ML6 0JS, UK Tel +44 I236 7/2759

Email g.ellis@nhs.net
Abstract: Changing global demography is resulting in older people presenting to emergency departments (EDs) in greater numbers than ever before. They present with greater urgency and are more likely to be admitted to hospital or re-attend and utilize greater resources. They experience longer waits for care and are less likely to be satisfied with their experiences. Not only that, but older people suffer poorer health outcomes after ED attendance, with higher mortality rates and greater dependence in activities of daily living or rates of admission to nursing homes. Older people's assessment and management in the ED can be complex, time consuming, and require specialist skills. The interplay of multiple comorbidities and functional decline result in the complex state of frailty that can predispose to poor health outcomes and greater care needs. Older people with frailty may present to services in an atypical fashion requiring detailed, multidimensional, and increasingly multidisciplinary care to provide the correct diagnosis and management as well as appropriate placement for ongoing care or admission avoidance. Specific challenges such as delirium, functional decline, or carer strain need to be screened for and managed appropriately. Identifying patients with specific frailty syndromes can be critical to identifying those at highest risk of poor outcomes and most likely to benefit from further specialist interventions. Models of care are evolving that aim to deliver multidimensional assessment and management by multidisciplinary specialist care teams (comprehensive geriatric assessment). Increasingly, these models are demonstrating improved outcomes, including admission avoidance or reduced death and dependence. Delivering this in the ED is an evolving area of practice that adapts the principles of geriatric medicine for the urgent-care environment.

Keywords: ED, frailty, models of care

\section{Population demography and its implications for the emergency department}

There can be no doubt that older people are presenting to emergency departments (EDs) in greater numbers every year. ${ }^{1-6}$ This is primarily due to increases in life expectancy ${ }^{1}$ and has been recognized to be the fastest growing sector of society in the developed world, representing a global phenomenon. ${ }^{7}$ The significance of this for the ED is that ED overcrowding is becoming more frequent. ${ }^{7}$ This has an important downstream effect, resulting in hospital overcrowding potentially compounding the problems in the ED. ${ }^{8}$

Older people are likely to use the ED at a higher rate than their younger counterparts, ${ }^{5}$ and there may be many reasons for this. Many common chronic diseases are seen in increasing frequency with advanced age, such as ischemic heart disease, diabetes mellitus, hypertension, cerebrovascular disease, dementia, and Parkinson's disease. ${ }^{9}$ Increased numbers of survivors with chronic diseases means increasing numbers of overlapping comorbidities and an increased risk of acute illness. ${ }^{7-9}$ This may be one 
of the reasons that older adults present to the ED with greater urgency than younger patients. ${ }^{5}$ Reduced exercise tolerance and cardiovascular fitness may also contribute to a picture of increased vulnerability. This picture is often further complicated by poly-pharmacy. ${ }^{10}$

Older adults who attend the ED are often sicker than younger patients due to these contributing factors. ${ }^{5,6}$ When they are reviewed in the ED they are likely to have longer lengths of stay. ${ }^{5,7,11}$ They are much more likely to be admitted to hospital than younger patients, ${ }^{5,7,11,12}$ and they are likely to have greater readmissions. ${ }^{5,13}$ Older patients incur greater health care treatment costs in the ED, ${ }^{5,6,11}$ and importantly are more likely to be admitted to institutional care following acute care. ${ }^{14}$

Significantly, older adults have much higher risks of poor health outcomes than younger patients. They have a higher mortality after ED attendance than younger patients. ${ }^{5,6}$ Not only that but they also record higher rates of dependence following ED attendance, requiring ongoing help and support with activities of daily living due to impairments of function or cognition. ${ }^{5}$

It would, however, be too easy to attribute poorer clinical outcomes for older people to medical factors. The presence of comorbidities and advanced age may mask the possibility that systems of care suit older patients less well, and this may be reflected in the fact that older people record higher dissatisfaction with ED care. ${ }^{15}$

\section{Assessing the older adult in the ED Frailty}

For older people, the onset of frailty marks the beginning of a different paradigm. Frailty is sometimes defined as the inability to withstand illness without loss of function or a loss of functional homeostasis. ${ }^{16,17}$ It is a complex interplay of multi-morbidity and aging physiology. Patients with frailty often present to services in a nonspecific fashion or with classic frailty syndromes such as falls, delirium, immobility, incontinence, carer strain, and social breakdown of care.

Additionally, it is recognized that ED physicians describe feeling less comfortable in dealing with older, more complex patients, ${ }^{15,18}$ and this may be the reason that discharge diagnoses from the ED are more often inaccurate in the older adult. ${ }^{5,19}$

Many older patients have multiple comorbidities that make assessment more complex, therefore requiring more time, which can be challenging in a time-pressured setting. Often history taking can be time consuming and may require corroborating history. Information on social background and medications can be difficult to obtain. Family members and service providers can prove crucial to providing this wider range of information. Associated health professionals can have a significant role to play in identifying deficits and addressing these. Increasingly, they have been demonstrating a successful impact even within the time-limited setting of an ED.

Background noise levels in the ED, especially at busy times, are difficult for patients with hearing impairment, just as complex environments with multiple unfamiliar visual stimuli can be difficult for patients with visual impairment or cognitive problems. The use of modified rooms or environments may be helpful but is not always possible. Simple measures such as increasing ambient light and reducing noise levels can be employed at minimal cost.

The initial triage, carried out at the "front door" of the acute hospital setting is a specialist process, which is developed for the rapid prioritization and management of life-threatening conditions. For older people, however, this triage has failed, in the past, to identify the many complexities which precipitate their admission. Assessment of cognitive impairment, functional problems, and existing home care must be seen as essential information for older adults in the ED. ${ }^{20-23}$

The nonspecific nature of the symptoms, with multiple simultaneous challenges or an unclear correlation between illness and presentation, can be bewildering. As we have seen, it takes time to adequately assess a patient across multiple domains, and the lack of multidisciplinary expertise can therefore mean that admission is considered the path of least resistance.

Patients presenting with problems across multiple domains simultaneously often need multiple professionals to appropriately assess their problems. Ideally, for instance, patients with immobility may require a physiotherapist to assess their mobility, a nurse to assess their continence, a psychiatric nurse to assess their mood, and a physician to assess their heart failure. The use of broad multidisciplinary teams to assess older patients in an organized and coordinated manner, referred to as comprehensive geriatric assessment (CGA), ${ }^{24}$ remains the mainstay of acute care for older patients.

\section{Functional impairment}

Functional problems such as a reduction in the ability to selfcare can lead to loss of independence and risk of institutionalization. Importantly, a decline in function can represent a presentation of underlying disease, which would explain its association with a higher mortality rate. ${ }^{25,26}$ It also represents 
Feeding: Are you able to feed yourself? Can you cut up food without help?

Bathing: Are you able to take a bath or shower without help? Are you confident to take a bath or shower with no one in the room or house?

Grooming: Do you need help with brushing hair, shaving, or applying make-up? Dressing: Can you get dressed without help? Can you manage buttons and laces?

Continence: Do you ever wet yourself if you are not able to get to the toilet in time? Do you ever soil or mess yourself with bowel motions?

Toileting: Do you need help to use the toilet?

Transfers: Are you able to get out of bed and on to a chair with no help?

Mobility: Are you able to walk 50 yards on the flat with no help? Do you use any walking aids such as a stick or frame? Have you fallen or stumbled in the past year?

Stairs: Are you able to climb a flight of stairs without help?

Figure I Key domains of the Barthel index.

Note: Data from Colin C, Wade DT, Davies S, Horne V. The Barthel ADL index: a reliability study. Int Disabil Studies. 1988;10:6I-63. ${ }^{27}$

Abbreviation: ADL, activities of daily living.

an opportunity to intervene and should be addressed if an older adult presents with symptoms of functional decline such as reduced mobility or difficulties with self-care. Assessment of function need not be difficult to assess in a trauma bay if simple semi-structured history taking is used such as one based on the Barthel index ${ }^{27}$ (Figure 1). Patients may require longer time for history taking, and corroborating history from family members can be very enlightening.

\section{Delirium and cognitive impairment}

Assessment of cognition in the older adult is essential in the ED. Identifying dementia and delirium can be critical to subsequent care and should never be missed.

In one series, as few as $38 \%$ of patients with severe cognitive impairment or delirium had this detected in the ED. ${ }^{28}$ Simple tools such as the four-question abbreviated mental test (AMT4) have relatively good sensitivity (90\%) for detecting impairment requiring further evaluation ${ }^{29}$ (Figure 2).

Delirium is said to be present in between $11 \%$ and $24 \%$ of older patients at admission to hospital and can develop subsequent to admission in a further $5 \%-35 \%$. $^{30,31}$

\section{Age? \\ 2. Date of birth? \\ 3. Place? \\ 4. Year?}

AMT4 (abbreviated mental test)

A score less than 4 is abnormal and should prompt further cognitive screening.

Figure 2 The four-question abbreviated mental test.
Delirium is known to have an association with poor outcome, and as such represents a significant marker of potentially important underlying disease. It is associated with increased hospital length of stay, admission to residential care, and death. ${ }^{32,33}$ For this reason, its recognition and management is critical, even in the first few hours of assessment.

Junior medical staff often under-recognize delirium, attributing it to chronic cognitive impairment or failing to adequately assess the patient's cognition. ${ }^{34,35}$

A variety of tools have been developed to aid the recognition of delirium, and the confusion assessment method is the most widely recognized of these and lends itself well to the ED. ${ }^{36}$ A more recent test (the 4AT) (Figure S1) has been developed however, designed to be used in an urgent-care setting with no special training, including the ability to test drowsy or agitated patients who are ordinarily difficult to assess. ${ }^{37}$ Conveniently, it also incorporates the AMT4 test. ${ }^{29}$

\section{Poly-pharmacy}

Poly-pharmacy can be defined as the regular use of multiple drugs, and yet it is recognized that the treatment of even a single condition (such as hypertension) may require a number of medications. This makes the avoidance of polypharmacy increasingly challenging among older adults. ${ }^{10}$ Often the reasons for multiple prescribing are driven by multiple comorbidities requiring long-term medical management. ${ }^{10}$ The significance of poly-pharmacy is the direct relationship between the numbers of co-prescribed agents and the frequency of serious drug-related interactions. ${ }^{10,38}$ 
Serious drug side effects leading to presentation at hospital are said to occur in over $10 \%$ of ED visits in adults over $65 .{ }^{39}$ The recognition of poly-pharmacy in an older patient represents an opportunity to intervene or to flag the issue for the patient's own general practitioner to intervene. Simple tools exist to guide clinicians in an evidence-based approach to the reduction in inappropriate prescribing and to encourage appropriate prescribing in the older adult. ${ }^{40}$ Medication reviews also present an opportunity to review patient concordance with drugs and potential opportunities to support this, such as home care supervision of medication.

\section{Falls}

Falls represent one of the single most common reasons an older adult will present at the ED. ${ }^{41}$ Approximately one in three people over the age of 65 will fall per year, with one in two people over the age of 80 falling at least once a year. ${ }^{42}$ In the ED, falls in the elderly result in admissions for $15 \%-30 \% 0^{11,41}$ and the incidence of fracture in this group is as much as $20 \% .{ }^{43}$ Even among patients without significant injury, a fall leading to an ED visit represents a significant marker for functional problems in up to $50 \%{ }^{44}$

Predictors of subsequent falls include a history of falls in the previous year, falling indoors, and inability to get up following a fall. ${ }^{45}$ Falls are a marker of frailty and an indication for detailed assessment and potentially onward referral for multidisciplinary review. Any patient over the age of 65 who falls should have a multifactorial assessment that includes assessment of cognition, continence, medication, mobility problems, postural instability, and visual impairment. This is in addition to screening for potential medical explanations for falls such as causes of syncope. ${ }^{42}$ Where possible, much of the assessment should be conducted in the ED; however, onward referral to falls' services for specialist multifactorial intervention is essential. ${ }^{42}$

In the $\mathrm{ED}$, the priorities must be the recognition and management of injury associated with a fall, the ruling out of significant underlying pathology, and the diagnosis of the cause of the fall.

One of the potentially most significant consequences of a fall is a fractured neck of femur, and older adults with frailty can have high mortality rates of up to $25 \%$ at 1 year following this. ${ }^{46}$ The priority in the ED following a hip fracture must be rapid identification, and management of potentially treatable comorbidities, such as anemia, hypovolemia, and electrolyte imbalance, to permit emergency surgery as early as possible. ${ }^{47}$
Head trauma associated with a fall should alert the ED physician to the possibility of a subdural hematoma if symptoms of headache, drowsiness, altered mental state, or focal neurological deficits follow the fall. ${ }^{48}$ Unfortunately, vigilance may be required as up to $50 \%$ of patients may not recall trauma. ${ }^{48}$

As with other presentations in the elderly, a fall may result as a consequence of underlying illness such as sepsis, cardiac causes, or medication changes. ${ }^{25}$

Multicomponent interventions designed to investigate and manage the causes of falls have been shown to be effective in reducing subsequent falls, admission to hospital, and functional decline in patients who present with a fall, to the ED. ${ }^{42,49,50}$

\section{Carers}

Carers of older people play an often fundamental role in the care of a patient attending the ED. They may provide the background history for the patient and confirm their current medications. In addition, and crucially in these patients, they can describe the patient's illness or frailty trajectories if given opportunity. This might mean the description of the patient's functional decline over years or months, unintended weight loss, cognitive change, or increased frequency and susceptibility to illness. ${ }^{51}$ They can also provide, on occasion, valuable insights into the patient's prior stated wishes where the patient lacks capacity.

They provide crucial supportive care in the home environment, and their strain may impact on a clinician's likelihood to admit. ${ }^{6}$ Involving carers in a discussion around a patient's care needs to be done sensitively and with tact, especially where a patient lacks capacity. ${ }^{52}$

For many older patients attending the ED, this level of complex need can be one determining factor for admission. Addressing carer strain is therefore important to a safe patient outcome. Enhancing access to social services, respite opportunities, home carers, day opportunities, community mental health teams, or primary care services may all be means of supporting a fragile carer situation and sustaining independent living for a frailer older adult.

\section{Nursing home}

One key group of ED attendees is the nursing-home resident. These patients are more likely to attend the ED than their non-residential peers. ${ }^{53}$ They tend to be older and are more likely to be female. ${ }^{53,54}$ They are more likely to present with an infective diagnosis ${ }^{53-55}$ or having recently been discharged.

Interestingly, in a large American series, older patients were significantly more likely to undergo more diagnostic 
tests or procedures than their counterparts and were much more likely to be admitted (odds ratio [OR] 1.8, 95\% confidence interval [CI] 1.6-2.0). ${ }^{54}$ This was replicated in an Australian study, which showed similar findings (OR 1.13, 95\% CI 1.06-1.20). ${ }^{55}$

Significantly, patients in residential care are considerably more likely to die in hospital (OR 1.57-2.3). ${ }^{53,54}$ This reflects the fact that nursing-home residents have far greater complexity and acuity than their independent counterparts. The UK National Audit Office study estimated that 50\% of hospital deaths from care homes residents were thought to be avoidable with better community care. One Canadian study examining the reasons for ED attendance noted that approximately one-quarter of ED attendances might have been preventable with better anticipatory care for common conditions. ${ }^{55}$

Strategies shown to be effective in reducing admissions include the earlier identification of patients with needs, and the use of advanced care plans to record the patient's wishes about their future care combined with better planning to reduce hospitalization. ${ }^{56,57}$ Over 2,500 care-homes have undertaken Gold Standards Framework (GSF) training, with on average a halving of hospital admissions and deaths due to this comprehensive whole-system approach, with many hundreds accredited and reaccredited three years later. ${ }^{58}$ These written anticipatory/advance care plans identify and record a patient's preference for their place of future care, their care priorities, or agreed ceilings of care. This might include treatment at home or in a care home in preference to hospital.

\section{Palliative care}

Recognizing and addressing progressive functional decline and limited prognosis may be crucial to discussing, planning, and prioritizing a patient's care needs. However, these skills and tasks may not be readily suited to the ED and are better delivered in the community. ${ }^{59-61}$ Identifying these needs and concerns can prove pivotal to preventing admission with anticipatory care or prioritizing the patient's wishes. Excellent tools and advice have been developed, such as the GSF Prognostic Indicator Guidance (PIG), ${ }^{51}$ designed to enable clinicians to approach the needs of people reaching an endof-life stage. The full GSF programs, used extensively in primary care, care homes, hospitals, and other settings, uses the PIG tool as the first step in the early identification of people in the final year of life. This leads to better clinical and personal needs assessment and planning care to meet these needs. The PIG tool includes the intuitive "surprise question",
Individuals who present with multiple comorbidities with significant impairment in day to day living and:

- Deteriorating functional score (eg, performance status Barthel)

- Combination of at least three of the following symptoms: - Weakness

- Slow walking speed

- Significant weight loss

- Exhaustion

- Low physical activity

- Depression

Figure 3 Frailty prognostic markers.

Note: Adapted from the Gold Standards Framework. Available from: http://www. goldstandardsframework.org.uk. Accessed May I, 20I4. ${ }^{51}$

generic indicators, and also specific indicators, such as those for frailty (Figure 3). It has been shown in various settings to improve early alerting of patients in the final year of life leading to more proactive care. ${ }^{62}$

\section{Age attuning hospital services}

If we design services for people with one thing wrong at once, but people with many things wrong turn up, the fault lies not with the system but with the service, yet too often these patients are termed inappropriate and labelled as a problem.

-Kenneth Rockwood ${ }^{63}$

Whilst we recognize that the admissions of older people represent the most significant single group for acute hospitals, ${ }^{64}$ increasingly it is becoming clear that older patients have distinct and complex care needs that are not suited to an episodic or specialty-focused care system. ${ }^{5,8,65}$

This represents a significant challenge to health services, many of which are designed for the needs of younger patients who may present with one problem in a more traditional fashion.

Older people are in reality a very heterogeneous population with varied needs; however, being able to dichotomize them on the basis of a frailty definition would better identify high-risk adults in need of specialist assessment. ${ }^{66}$ For the ED, managing patient flows and seeking the appropriate setting for further care relies on the correct identification of appropriate patients. The scientific definitions of frailty, however, do not lend themselves easily to operationalized tools for the ED. Many different frailty tools have been developed, all of which have limited utility in the urgent-care setting but may be better than nothing. ${ }^{67}$ The commonest of these is the Identification of Seniors at Risk. ${ }^{68,69}$ This short, self-administered screening tool evaluates functional dependence, recent 
hospitalization, memory impairment, visual impairment, and polypharmacy (Figure 4). The tool is easy to apply in an urgent-care setting and does identify risk of adverse outcome but has limited predictive ability. ${ }^{67}$ Other tools include the Triage Risk Stratification Tool or the Older Adult Resources and Services tool. ${ }^{70}$

Many services have developed specialist in-reach teams to address this issue, such as National Health Service (NHS) Lanarkshire's Acute Care for Elderly (ACE) Nurses. ${ }^{71}$ Similar nurse practitioner-led case-finding models have been trialed, ${ }^{72}$ with reductions in nursing home admissions seen at 30 days. ${ }^{73}$ The purpose of these services is to commence the CGA process at the earliest opportunity, with the primary aim of improving the quality of care and ultimately the outcomes for older people. Broadly, these specialist in-reach services aim to undertake a number of roles including the key role of specialist case finding to identify appropriate patients where screening tools delivered by non-specialists may fall short. They have the ability to start medical, functional, cognitive, and social assessment. They will often liaise with family or informal carers as well as a range of agencies at the interface of care, to promote safe early discharges or clarify patient needs. They may be able to support medicine reconciliation, which can be a crucial safety priority. Significantly, they need to ensure signposting of people appropriate for admission to CGA wards, or identify those safe for discharge. They are best placed to link with existing associated health professionals where needs are identified or with the geriatrician. One advantage of having specialist in-reach staff is the ability to develop, practice, and enhance skills. They can increase capability and capacity within the non-specialist workforce in order to make a significant contribution to the delivery of quality and timely care.
Allied health professionals have a key role to play within the ED, medical receiving units, and assessment bays. Having dedicated occupational therapy and physiotherapy over 7 days can enhance the senior decision-making team significantly. ${ }^{74}$ Importantly, that broader assessment of function, mobility, and self-care provides key information about the patient's abilities as well as enhancing the planning of discharge. Having that expertise can facilitate rapid, safe discharge or admission avoidance, but can also provide diagnostic insights on problems presenting as impairment of function. Crucially, of course, the timely intervention can prevent further functional decline - anticipating factors leading to increased dependence with its consequent health risks. The development therefore of multidisciplinary in-reach teams can enhance ED capacity, diagnostics, and patient flows, including safe discharge.

\section{Established interventions}

Evidence-based services exist for frailer older adults, including those that occur after admission, (inpatient CGA), those that shorten admission or facilitate safe discharge (early supported discharge), and alternatives to admission (day hospital, admission avoidance hospital at home).

For older patients that require admission to hospital there is evidence that those patients admitted to a specialty service (CGA) are more likely to be alive and in their own homes at the end of follow-up than those admitted to a general medical ward. ${ }^{75}$ The evidence is strongest for units with discrete beds. Additional benefits include improved cognition, reduced death or dependence and reduced institutionalization.

One of the unanswered questions centers on which patients should be admitted to specialty beds. The evidence appears stronger in the subgroup of frail and high-risk patients

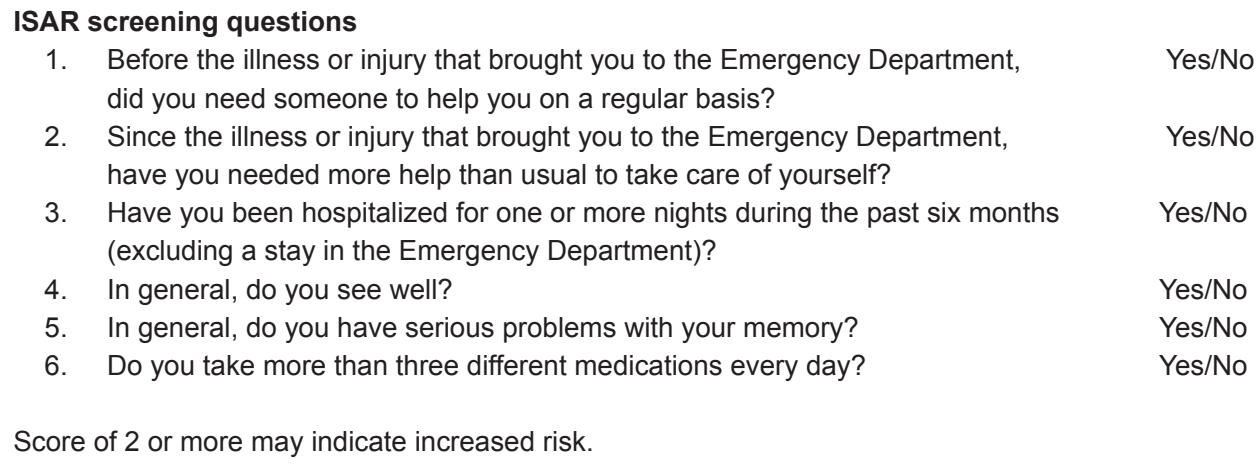

Figure 4 The Identification of Seniors at Risk (ISAR) screening tool.

Note: Data from McCusker J, Bellavance F, Cardin S, Trepanier S, Verdon J, Ardman O. Detection of older people at increased risk of adverse health outcomes after an emergency visit: the ISAR screening tool. J Am Geriatr Soc. 1999;47:1229-1237.69 
such as those at risk of nursing-home admission, those presenting with classic geriatric syndromes (such as falls and immobility), and those with cognitive impairment.

Admission to hospital for older people with frailty, however, is not without its risk. Older people are at risk of rapid decline in functional ability and of delirium when they are admitted to hospital. This is partly explained by restrictions imposed by the hospital environment which limit their range of activities, and that such environments place undue stress on people with limited cognitive reserve. For instance, an estimated $12 \%$ of patients may experience a decline in function following admission to a hospital setting. ${ }^{76,77}$ Similarly, incidence rates of delirium following admission have varied in prospective studies between $3 \%$ and $29 \%$, with some recognized risk factors. ${ }^{78}$ In addition, the relationship between the patient and their carer is interrupted and can be difficult to reestablish.

In view of the increasing rate of admissions in the elderly, it is not uncommon for policy makers to assume that the solution to acute care pressures is to prevent older people attending hospital EDs. The danger of such policy statements is that they could potentially deny access for sick or vulnerable adults who require secondary care services and employ a form of institutional ageism. The emphasis therefore needs to be on the "appropriate care in the appropriate setting."

Additionally, safe, sustainable, patient-centered alternatives to the ED can provide a wider range of options available for the older adult in an acute crisis and avoid the necessity of lengthy or inappropriate inpatient assessment.

This might include outpatient CGA, which allows ambulatory care, assessment, diagnostics and rehabilitation, whilst keeping the patient in their own home. Reviews demonstrated a reduction in death or a poor outcome when day hospital was compared with no comprehensive elderly care at follow-up. ${ }^{79}$

Admission avoidance hospital at home is a service that provides active treatment by health care professionals in the patient's own home for a condition that otherwise would require acute hospital admission. ${ }^{80}$ Data from a Cochrane review of randomized controlled trials showed a significant reduction in mortality at 6 months for patients with a range of conditions treated in the hospital at home arm in addition to improved patient satisfaction and reduced costs. Further data are needed to bolster this small but important evidence base, but it may be that in the future we need to develop further services to provide safe alternatives to inpatient care without disenfranchising elderly patients.
Other strategies to reduce hospital bed days for older adults include early supported discharge schemes, which have been shown to reduce nursing home admissions and dependence whilst reducing hospital length of stay and providing alternative routes out of the ED..$^{81,82}$

\section{Emergent interventions}

There are a number of evolving interventions designed to address the needs of older people in the ED. ${ }^{83}$ These interventions have sometimes collectively been referred to as interface geriatrics. This is an evolving role for geriatrics in the hospital system. ${ }^{84}$ One model that is becoming more common is the use of discrete beds in the ED. These are geared for older patients with a specialist multidisciplinary team including geriatricians who review patients with the aim of providing immediate comprehensive multidisciplinary assessment leading to direct admission or admission avoidance. ${ }^{85,86}$ The argument for discrete beds shadows the evidence from CGA studies, ${ }^{87}$ suggesting that discrete units may have environmental benefits, but perhaps more importantly foster consistent practice and the development of expertise. Some of these models have demonstrated reductions in length of stay or readmission, although as yet, randomized controlled trials are few. One randomized controlled trial evaluated the impact of a geriatrician assessment in the medical admissions unit. ${ }^{88}$ This did not demonstrate significant improvements in days spent at home (in preference to institutional care), mortality, or other secondary outcomes. This trial, however, did not utilize full multidisciplinary teams to evaluate patients, and in this respect may not represent full CGA.

More multidisciplinary models of care combined with discharge support or alternatives to admission may demonstrate larger impacts on length of stay ${ }^{89}$ and nursing home admission. $^{74}$

In some countries where economies of scale have permitted, hospitals have set up specialist EDs. ${ }^{90}$ These are discrete departments specifically designed for older adults, with specialist staff and environments geared for appropriate assessment. The establishment of specialist centers with EDs specifically for older patients may not be possible in all settings. This can be dependent on the local health care economy; however, they may allow the development of further research and expertise that can be applied in other settings. In the United States, guidelines have been developed for the geriatric ED as a collaboration between the societies of emergency medicine, nursing, and geriatrics. ${ }^{20}$ Similar guidelines also exist in the UK. ${ }^{91}$ The standards agreed across 
multi professional agencies will allow the adoption of best practice ideally irrespective of the setting.

\section{The future}

Looking forward with a changing demographic of older people's requirements for acute care, we need to create systems in the 21 st century that put their needs at the core of the ED. Radical redesign may be necessary to help health services provide safe and sustainable patient-centered care across the full 7 days of the week. This will include greater provision of acute geriatric assessment in the ED and ready access to CGA services on admission or discharge. Inevitably, it must include strategies that provide safe alternatives to admission. In many respects, it is the most vulnerable who will have most to lose from systems that are unsafe or inadequately designed to address their needs. The frail elderly represent arguably the largest cohort for whom this is true.

\section{Disclosure}

The authors declare no conflicts of interest.

\section{References}

1. OECD Library of Statistics. Available from: http://www.oecd-ilibrary. org/docserver/download/190800081e1t008.pdf?expires=1408528298\& $\mathrm{id}=\mathrm{id} \&$ accname $=$ freeContent $\&$ checksum $=\mathrm{D} 17 \mathrm{~A} 40 \mathrm{C} 72 \mathrm{BA} 4 \mathrm{DD} 86 \mathrm{~B} 09$ D7E9EE6547989. Accessed August 20, 2014.

2. Spijker J, Macinnes J. Population ageing: the time-bomb that isn't? BMJ. 2013;347:20-22.

3. Hospital Episode Statistics Analysis. Hospital Episode Statistics: Accident and Emergency Attendances in England 2012-13. January 2014. Available from: http://www.hscic.gov.uk/article/2021/Website-Search?prod uctid $=14120 \& q=$ accident + and + emergency + attendances + in + england + 2012-13\&sort=Relevance\&size $=10 \&$ page $=1 \&$ area $=$ both\#top. Accessed August 26, 2014.

4. Downing A, Wilson R. Older people's use of accident and emergency services. Age Ageing. 2005;34(1):24-30.

5. Aminzadeh F, Dalziel WB. Older adults in the emergency department: a systematic review of patterns of use, adverse outcomes, and effectiveness of interventions. Ann Emerg Med. 2002;39(3):238-247.

6. Samara N, Chevalley T, Samaras D, Gold G. Older patients in the emergency department: a review. Ann Emerg Med 2010;56(3): 261-269.

7. Roberts DC, McKay MP, Shaffer A. Increasing rates of emergency department visits for elderly patients in the United States, 1993-2003. Ann Emerg Med. 2008;51(6):769-774.

8. Future Hospital Commission. Future hospital: caring for medical patients. A report from the Future Hospital Commission to the Royal College of Physicians. London: The Royal College of Physicians; 2013. Available from: https://www.rcplondon.ac.uk/sites/default/files/futurehospital-commission-report.pdf. Accessed August 26, 2014.

9. Barnett K, Mercer S, Norbury M, Watt G, Wyke S, Guthrie B. The epidemiology of multimorbidity in a large cross-sectional dataset: implications for health care, research and medical education. Lancet. 2012;380:37-43.

10. Guthrie B, Makubate B. The rising tide of polypharmacy and potentially serious drug interactions 1995-2010: repeated cross sectional analysis of dispensed prescribing in one region. Prim Health Care Res Dev. 2012;13(1):45.
11. Singal BM, Hedges JR, Rosseau EW, et al. Geriatric patient emergency visits. Part 1: comparison of visits by geriatric and younger patients. Ann Emerg Med. 1992;21(7):802-807.

12. Imison $\mathrm{C}$, Poteliakhoff $\mathrm{E}$, Thompson J. Older people and emergency bed use. Exploring variation. Ideas that change healthcare. London: The Kings Fund, 2012. Available from: http://www.kingsfund.org.uk/ sites/files/kf/field/field_publication_file/older-people-and-emergencybed-use-aug-2012.pdf. Accessed August 26, 2014.

13. McCusker J, Bellavance F, Cardin S, Belzile E, Verdon J. Prediction of hospital utilisation among elderly patients during 6 months after an emergency department visit. Ann Emerg Med. 2000;36(5): 438-445.

14. Sager MA, Franke T, Inouye SK, et al. Functional outcomes of acute medical illness and hospitalisation in older persons. Arch Intern Med. 1996;156:645-652.

15. Grief CL. Patterns of ED use and perceptions of the elderly regarding their emergency care: a synthesis of recent research. JEmerg Med. 2007; 22:1527-1531.

16. Carlson JE, Zocchi KA, Bettencourt DM, et al. Measuring frailty in the hospitalised elderly: concept of functional homeostasis. Am J Phys Med Rehabil. 1998;77(3):252-257.

17. Wells JL, Seabrook JA, Stolee P, Borrie MJ, Knoefel F; State of the art in geriatric rehabilitation. 1. Review of frailty and comprehensive geriatric assessment. Arch Phys Med Rehabil. 2003;84:890-897.

18. McNamara R, Rosseau E, Sanders AB. Geriatric emergency medicine: a survey of practiticing emergency physicians. Ann Emerg Med. 1992; 21:796-801.

19. Sanders AB, Morley JE. The older person in the emergency department. J Am Geriatr Soc. 1993;41:880-882.

20. American College of Emergency Physicians [homepage on the Internet]. Geriatric Emergency Department Guidelines. Available from: http:// www.acep.org/geriEDguidelines. Accessed May 1, 2014.

21. Wilber ST, Lofgren SD, Mager TG, Blanda M, Gerson LW. An evaluation of two screening tools for cognitive impairment in older adults in an emergency department. Acad Emerg Med. 2005;12:612-616.

22. Carpenter CR, DesPain B, Keeling TN, Shah MS, Rothenberger M. The six-item screener and AD8 for the detection of cognitive impairment in geriatric emergency department patients. Ann Emerg Med. 2011;57(6):653-661.

23. Healthcare Improvement Scotland. Improving the identification and management of frailty: a case study report of innovation on four acute sites in Edinburgh: NHS Scotland. 2014. Available from: http://www. healthcareimprovementscotland.org/our_work/person-centred_care/ opac_improvement_programme/frailty_report.aspx. Accessed August 26, 2014.

24. Rubensein LZ, Stuck AE, Siu AL, Wieland D. Impact of geriatric evaluation and management programmes on defined outcomes: overview of the evidence. J Am Ger Soc. 1991;39:8-16.

25. Schumacher JG. Emergency medicine and older adults: continuing challenges and opportunities. Am J Emerg Med. 2005;23(4): $556-560$.

26. Cooper R, Kuh D, Hardy R. Objectively measured physical capability levels and mortality: systematic review and meta-analysis. $B M J$. 2010;341(7774):639.

27. Colin C, Wade DT, Davies S, Horne V. The Barthel ADL index: a reliability study. Int Disabil Studies. 1988;10:61-63.

28. Hustey F, Meldon S, Smith M, Lex C. The effect of mental status screening on the care of elderly emergency department patients. Ann Emerg Med. 2003;41(5):678-684.

29. Swain DG, Nightingale PG. Evaluation of a shortened version of the abbreviated mental test in a series of elderly patients. Clin Rehabil. 1997; 11(3):243-248.

30. Inouye SK. Delirium in the hospitalized older patients. Clin Geriatr Med. 1998;14(4):745-764.

31. Chong MS, Chan M, Tay L, Yoong Ding Y. Outcomes of an innovative model of acute delirium care: the geriatric monitoring unit (GMU). Clin Interv Aging. 2014;9:603-612. 
32. National Clinical Guideline Centre. DELIRIUM: diagnosis, prevention and management clinical guideline 103. London: National Institute for Health and Clinical Excellence, 2010.

33. Han JH, Shintani A, Eden S, et al. Delirium in the emergency department: an independent predictor of death within 6 months. Ann Emerg Med. 2010;56(3):244-252.

34. Armstrong SC, Cozza KL, Watanabe KS. The misdiagnosis of delirium. Psychosomatics. 1997;38:433-439.

35. Inouye SK, Foreman MD, Mion LC, Katz KH, Cooney LM Jr. Nurses' recognition of delirium and its symptoms: comparison of nurse and researcher ratings. Arch Intern Med. 2001;161(20):2467-2473.

36. Inouye SK, van Dyck CH, Alessi CA, Balkin S, Siegal AP, Horwitz RI. Clarifying confusion: the confusion assessment method. A new method for detection of delirium. Ann Intern Med. 1990;113(12): 941-948.

37. Bellelli G, Morandi A, Davis D, et al. Validation of the 4AT, a new instrument for rapid delirium screening: a study in 234 hospitalised older people. Age Ageing. 2014;43(4):496-502.

38. Viktil KK, Blix HS, Moger TA, Reikvam A. Polypharmacy as commonly defined is an indicator of limited value in the assessment of drug-related problems. Br J Clin Pharmacol. 2007;63(2):187-195.

39. Hohl CM, Dankoff J, Colacone A, Afilalo M. Polypharmacy, adverse drug-related events, and potential adverse drug interactions in elderly patients presenting to the emergency department. Ann Emerg Med. 2001; 38:666-671.

40. Gallagher P, Ryan C, Byrne S, Kennedy J, O’Mahony D. STOPP (Screening Tool of Older Persons' Prescriptions) and START (Screening Tool to Alert Doctors to Right Treatment): Consensus Validation. Int J Clin Pharmacol Ther. 2008;46(2):72-83.

41. Vanpee D, Swine C, Vandenbossche P, Gillet JB. Epidemiological profile of geriatric patients admitted to the emergency department of a university hospital localized in a rural area. Eur J Emerg Med. 2001; 8(4):301-304.

42. National Institute for Clinical Excellence. NICE clinical guideline 161 Falls: assessment and prevention of falls in older people. June 2013 Available from: http://www.nice.org.uk/guidance/CG161/chapter/ introduction. Accessed August 26, 2014.

43. Davies AJ, Kenny RA. Falls presenting to the accident and emergency department: types of presentation and risk factor profile. Age Ageing 1996;25:362-366.

44. Farnworth TA, Waine S, McEvoy A. Subjective assessment of additional support requirements of elderly patients discharged from an accident and emergency department. J Accid Emerg Med. 1995;12:107-110.

45. Close JCT, Hooper R, Glucksman E, Jackson SHD, Swift CG. Predictors of falls in a high risk population: results from the prevention of falls in the elderly trial (PROFET). Emerg Med J. 2003;20:42.

46. Schurch MA, Rizzoli R, Mermillod B, Vasey H, Michel JP, Bonjour JP. A prospective study on socioeconomic aspects of fracture of the proximal femur. J Bone Min Res. 1996;11:1935-1942.

47. National Institute for Clinical Excellence. NICE Clinical Guideline 124. The management of hip fracture in adults. June 2011. Last modified: March 2014. Available from http://www.nice.org.uk/guidance/cg124/ chapter/introduction. Accessed August 26, 2014.

48. Adhiyaman V, Ashghar M, Ganeshram KN, Bhowmick BK. Chronic subdural haematoma in the elderly. Postgrad Med J. 2002;78: 71-75.

49. Close J, Ellis M, Hooper R, Glucksman E, Jackson S, Swift C. Prevention of falls in the elderly trial (PROFET): a randomised controlled trial. Lancet. 1999;9147(353):93-97.

50. Davison J, Bond J, Dawson P, Steen IN, Kenny RA. Patients with recurrent falls attending Accident and Emergency benefit from multifactorial intervention - a randomized controlled trial. Age Ageing. 2005;34: $162-168$.

51. The Gold Standards Framework. Available from: http://www.goldstandardsframework.org.uk. Accessed May 1, 2014.

52. General Medical Council. Good Medical Practice. Manchester: General Medical Council; 2013.
53. Ingarfield SL, Finn JC, Jacobs IG, et al. Use of emergency departments by older people from residential care: a population based study. Age Ageing. 2009;38:314-318.

54. Wang HE, Shah MN, Allman RM, Kilgore M. Emergency department visits by nursing home residents in the United States. J Am Geriatr Soc. 2011;59:1864-1872.

55. Grunier A, Bell CM, Bronskill SE, Schull M, Anderson GM, Rochon PA. Frequency and pattern of emergency department visits by long-term care residents - a population based study. J Am Geriatr Soc. 2010;58: 510-517.

56. Molloy DW, Guyatt GH, Russo R, et al. Systematic implementation of an advance directive program in nursing homes: a randomized controlled trial. JAMA. 2000;283(11):1437-1444.

57. Robinson L, Dickinson C, Rousseau N, et al. A systematic review of the effectiveness of advance care planning interventions for people with cognitive impairment and dementia. Age Ageing. 2012;41(2): 263-269.

58. The Gold Standards Framework. Summary of Evidence for Gold Standards Framework Care Homes Training programme National GSF Centre August 2012. Shrewsbury, UK: The Gold Standards Framework. Available from: http://www.goldstandardsframework. org.uk/cd-content/uploads/files/Library\%2C\%20Tools $\% 20 \% 26 \% 20$ resources/Summary $\% 20$ of $\% 20$ GSFCH $\% 20$ Effectiveness $\% 20 \% 26 \% 20$ Evidence\%20-\%20Updated\%20by\%20MD\%20August\%202012(1). pdf. Accessed October 29, 2014.

59. Thomas K. Prognostic Indicator Guidance (PIG) 4th Edition. Oct 2011 The Gold Standards Framework Centre. In: End of Life Care, CIC.

60. Gwilliam B, Keeley V, Todd C, et al. Development of Prognosis in Palliative Care Study (PiPS) predictor models to improve prognostication in advanced cancer: prospective cohort study. BMJ. 2011;343:d4920

61. SPICT. Available from: http://www.spict.org.uk. Accessed May 1, 2014.

62. Gott M, Frey R, Raphael D, O’Callaghan A, Robinson J, Boyd M. Palliative care need and management in the acute hospital setting: a census of one New Zealand Hospital. BMC Palliat Care. 2013;12:15.

63. Rockwood K. What would make a definition of frailty successful? Age Ageing. 2006;34:33-34.

64. Cornwell J, Levenson R, Sonola L, Poteliakhoff E. Continuity of Care for Older Hospital Patients: a call for action. London: King's Fund; 2012.

65. Conroy S, Ferguson C, Woodard J, Banerjee J. Interface geriatrics: evidence-based care for frail older people with medical crises. $\mathrm{Br} J$ Hosp Med. 2010;71(2):98-101.

66. Goldstein JP, Andrew MK, Travers A. Frailty in older adults using pre-hospital care and the emergency department: a narrative review. Can Geriatr J. 2012;15(1):16-22.

67. Wou F, Gladman JRF, Bradshaw L, Franklin M, Edmans J, Conroy SP. The predictive properties of frailty-rating scales in the acute medical unit. Age Ageing. 2013;42:776-781.

68. Edmans J, Bradshaw L, Gladman JRF, et al. The Identification of Seniors at Risk (ISAR) score to predict clinical outcomes and health service costs in older people discharged from UK acute medical units. Age Ageing. 2013;42: 747-753.

69. McCusker J, Bellavance F, Cardin S, Trepanier S, Verdon J, Ardman O. Detection of older people at increased risk of adverse health outcomes after an emergency visit: the ISAR screening tool. J Am Geriatr Soc. 1999;47:1229-1237.

70. Bissett M, Cusick A, Lannin NA. Functional assessments utilised in emergency departments: a systematic review. Age Ageing. 2013;42: $163-172$.

71. Ellis G, Jamieson C-A, Alcorn M, Devlin V. An acute care for elders (ACE) unit in the emergency department. Eur Geriatr Med. 2012;3(4): 261-263.

72. Howell F. Frail Elderly Assessment Unit (FEAU): current challenges and future potentials. Available from: https://www.rcn.org.uk/_data/ assets/pdf_file/0004/448465/Howell,_Fiona_.pdf. Accessed May 1, 2014. 
73. Mion LC, Palmer RM, Meldon SW, et al. Case finding and referral model for emergency department elders: a randomised clinical trial. Ann of Emerg Med. 2003;41(1):57-68.

74. Royal College of Physicians. Acute Medical Care. The Right Person, in the Right Setting - First Time. Report of the Acute Medicine Task Force. London: The Royal College of Physicians; 2007.

75. Ellis G, Whitehead MA, O’Neill D, Langhorne P, Robinson D. Comprehensive geriatric assessment for older adults admitted to hospital. Cochrane Database Syst Rev. 2011;7:CD006211.

76. Covinsky KE, Palmer RM, Fortinsky RH, et al. Loss of independence in activities of daily living in older adults hospitalised with medical illness: increased vulnerability with age. J Am Geriatr Soc. 2003;51: 451-458.

77. Mudge AM, O'Rourke P, Denaro CP. Timing and risk factors for functional changes associated with medical hospitalisation in older patients. J Gerontol A Biol Sci. 2010;65:866-872.

78. Siddiqi N, House AO, Holmes JD. Occurrence and outcome of delirium in medical in-patients: a systematic literature review. Age Ageing. 2006; 35:350-364.

79. Forster A, Young J, Lambley R, Langhorne P. Medical day hospital care for the elderly versus alternative forms of care. Cochrane Database Syst Rev. 2008;4:CD001730.

80. Shepperd S, Doll H, Angus RM, et al. Hospital at home admission avoidance. Cochrane Database Syst Rev. 2008;4:CD007491.

81. Shepperd S, Doll H, Broad J, et al. Hospital at home early discharge. Cochrane Database Syst Rev. 2009;1:CD000356.

82. Beswick AD, Rees K, Dieppe P, et al. Complex interventions to improve physical function and maintain independent living in elderly people: a systematic review and meta-analysis. Lancet. 2008; 371(9614):725-735.
83. Conroy S. Emergency room geriatric assessment - urgent, important or both? Age Ageing. 2008;37:612-613.

84. Conroy S, Ferguson C, Banerjee J. Interface geriatrics: an evidence based solution for frailer older people with medical crisis. Br J Hosp Med. 2010;71:98-101.

85. Conroy SP, Ansari K, Williams M, et al. A controlled evaluation of comprehensive geriatric assessment in the emergency department: the “emergency frailty unit". Age Ageing. 2014;43(1):109-114.

86. Ellis G, Jamieson C-A, Alcorn M, Devlin V. An acute care for elders (ACE) unit in the emergency department. Eur Geriatr Med. 2012;3(4): 261-263.

87. Ellis G, Whitehead MA, Robinson D, O’Neill D, Langhorne P. Comprehensive geriatric assessment for older adults admitted to hospital: meta-analysis of randomised controlled trials. BMJ. 2011;343:d6553.

88. Edmans J, Bradshaw L, Franklin M, Gladman J, Conroy S. Randomised controlled trial of specialist geriatric medical assessment for patients discharged from hospital acute assessment units. $B M J$. 2013;347:f5874.

89. Wright PN, Tan G, Iliffe S, Lee D. The impact of a new emergency admission avoidance system for older people on length of stay and same-day discharges. Age Ageing. 2014;43:116-121.

90. Hogan TM, Olade TO, Carpenter CR. A profile of acute care in an aging America: snowball sample identification and characterization of United States geriatric emergency departments in 2013. Acad Emerg Med. 2014;21(3):337-346.

91. Cooke M, Oliver D, Burns A. Quality Care for Older People with Urgent and Emergency Care Needs. Available from: http://www.bgs. org.uk/campaigns/silverb/silver_book_complete.pdf. Accessed May 1, 2014 


\section{Supplementary material}

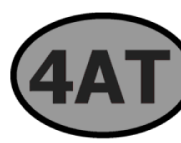

The 4 'A's Test: screening instrument for delirium and cognitive impairment

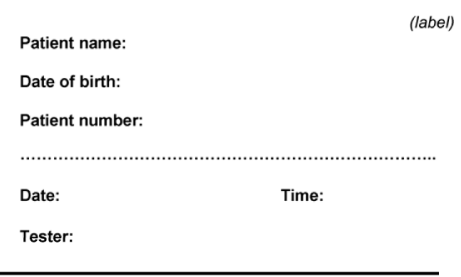

CIRCLE

\section{[1] ALERTNESS}

This includes patients who may be markedly drowsy (eg. difficult to rouse and//or obviously sleepy during assessment) or agitated/hyperactive. Observe the patient. If asleep, attempt to wake with

$\begin{array}{ll}\text { Normal (fully alert, but not agitated, throughout assessment) } & 0 \\ \text { Mild sleepiness for }<10 \text { seconds after waking, then normal } & 0\end{array}$

Clearly abnormal

[2] AMT4

Age, date of birth, place (name of the hospital or building), current year.

No mistakes

1 mistake

2 or more mistakes/untestable (label)

\section{[3] ATTENTION}

The partient: "Please tell me the months of the year in backwards order, starting at December-" To assist initial understanding one prompt of "what is the month before December?" is permitted.

Months of the year backward

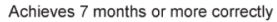

2

[4] ACUTE CHANGE OR FLUCTUATING COURSE

Evidence of significant change or fluctuation in: alertness, cognition, other mental function
(eg. paranoia, hallucinations) arising over the last 2 weeks and still evident in last $24 \mathrm{hrs}$

No
Yes

4 or above: possible delirium +/- cognitive impairment

1-3: possible cognitive impairment

0 : delirium or severe cognitive impairment unlikely (but

delirium still possible if [4] information incomplete)

Version 1.1. Information and download: www.the4AT.com
GUIDANCE NOTES
The 4AT is a screening instrument designed for rapid initial assessment of delirium and cognitive impairment. A score of 4 or The 4AT is a screening instrument designed for rapid initial assessment of delirium and cognitive impairment. A score of 4 or
more suggests delirium but is not diagnostic: more detailed assessment of mental status may be required to reach a diagnosis. A more suggests delirium but is not diagnostic: more detailed assessment of mental status may be required to reach a diagnosis. A
score of $1-3$ suggests cognitive impairment and more detailed cognitive testing and informant history-taking are required. A score of 0 does not definitively exclude delirium or cognitive impairment: more detailed testing may be required depending on the clinical context. Items 1-3 are rated solely on observation of the patient at the time of assessment. Item 4 requires information from one or more source(s), eg. your own knowledge of the patient, other staff who know the patient (eg. ward nurses), GP letter, case notes, carers. The tester should take account of communication difficulties (hearing impairment, dysphasia, lack of common language) when carrying out the test and in

Alertness: Altered level of alertness is very likely to be delirium in general hospital settings. If the patient shows significant altered alertness during the bedside assessment, score 4 for this item. AMT4 (Abbreviated Mental Test - 4): This score can be can occur without delirium in some cases of dementia, but marked fluctuation usually indicates delirium. To help elicit any hallucinations and/or paranoid thoughts ask the patient questions such as, "Are you concerned about anything going on here?": "Do you feel frightened by anything or anyone?"; "Have you been seeing or hearing anything unusual?"

Figure SI 4AT tool.

Note: Reproduced from MacLullich A, Ryan T, Cash H. The 4 'A's Test: screening for delirium and cognitive impairment [webpage on the Internet]. Edinburgh, Scotland: University of Edinburgh. Available from: http://www.the4at.com. Accessed August 26, 20I4.'

\section{Reference}

1. MacLullich A, Ryan T, Cash H. The 4 'A's Test: screening for delirium and cognitive impairment [webpage on the Internet]. Edinburgh, Scotland: University of Edinburgh. Available from: http://www.the4at. com. Accessed August 26, 2014.

Clinical Interventions in Aging

Dovepress

\section{Publish your work in this journal}

Clinical Interventions in Aging is an international, peer-reviewed journal focusing on evidence-based reports on the value or lack thereof of treatments intended to prevent or delay the onset of maladaptive correlates of aging in human beings. This journal is indexed on PubMed Central, MedLine,
CAS, Scopus and the Elsevier Bibliographic databases. The manuscript management system is completely online and includes a very quick and fair peer-review system, which is all easy to use. Visit http://www.dovepress. com/testimonials.php to read real quotes from published authors. 